\title{
Transcription start sites and epigenetic analysis of the HSD17B10 proximal promoter
}

\author{
Song-Yu Yang ${ }^{1 *}$, Carl Dobkin ${ }^{2}$, Xue-Ying He ${ }^{1}$ and W Ted Brown²
}

\begin{abstract}
Background: Hydroxysteroid (17beta) dehydrogenase X (HSD10) is a multifunctional protein encoded by the HSD17B10 gene at Xp11.2. In response to stress or hypoxia-ischemia its levels increase rapidly. Expression of this gene is also elevated significantly in colonic mucosa of the inactive ulcerative colitis patients. However, accurate information about its several transcripts is still lacking, and additional evidence for its escape from X-chromosome inactivation remains to be obtained in order to help settle a debate (He XY, Dobkin C, Yang SY: Does the HSD17B10 gene escape from X-inactivation? Eur J Hum Genet 2011, 19: 123-124).

Results: Two major HSD17B10 transcription start sites were identified by primer extension at -37 and -6 as well as a minor start site at -12 nucleotides from the initiation codon ATG. Epigenetic analysis of the 5 '-flanking region of the HSD17B10 gene showed that there was little 5-methylcytosine $(<3 \%)$ in a normal male, and that none of CpG dinucleotides in the CpG island approached $50 \%$ methylation in females.

Conclusion: The actual length of first exon of the HSD17B10 gene was found to be about a quarter larger than that originally reported. Its transcripts result from a slippery transcription complex. The hypomethylation of the CpG island provides additional evidence for the variable escape of the HSD17B10 gene from X-chromosome inactivation which could influence the range of severity of HSD10 deficiency, an inherited error in isoleucine metabolism, in heterozygous females.
\end{abstract}

Keywords: CpG island, DNA methylation, TATA-less promoter, X-chromosome inactivation, HSD10 deficiency

\section{Background}

Hydroxysteroid (17beta) dehydrogenase $\mathrm{X}$ (HSD10) is encoded by the HSD17B10 gene at Xp11.2 [1]. HSD10 is a multifunctional enzyme involved in the degradation of isoleucine and branched-chain fatty acids, the metabolism of steroid hormones and neuroactive steroids as well as aldehyde detoxification $[2,3]$. Furthermore, it complexes with other proteins to generate RNase P activity [4]. Various HSD10 functions are inhibited when it is bound to the amyloid- $\beta$ peptide [5] or estrogen receptor alpha [6].

Mutations in the HSD17B10 gene and its aberrant expression result in HSD10 deficiency (OMIM\#300438) $[7,8]$, X-linked mental retardation, and abnormal behavior (MRXS10) (OMIM\#300220) [9]. Accumulation of HSD10 in neurons is also involved in the pathogenesis of Alzheimer disease (AD) [10]. Elevated levels of

\footnotetext{
* Correspondence: songyu.yang@csi.cuny.edu

'Department of Developmental Biochemistry, NYS Institute for Basic Research in Developmental Disabilities, 1050 Forest Hill Road, Staten Island, NY 10314, USA
} Full list of author information is available at the end of the article
HSD10 are found in the cerebrospinal fluid (CSF) of patients with $\mathrm{AD}$ and multiple sclerosis [11]. HSD10 levels vary significantly among different brain regions and in response to stress and hypo-ischemia [12,13]. The expression of the HSD17B10 gene was also significantly elevated in colonic mucosa of the inactive ulcerative colitis patients $[14,15]$. In order to lay the foundation for designing effective treatment of these disease conditions, it is essential to elucidate the molecular mechanism of the $H S D 17 B 10$ gene's expression. For this reason we sought accurate information about its transcripts and DNA methylation of its CpG island.

Here we report that there are several transcription start sites. The predominant transcript, HSD10 variant 1 , starts at -37 or -6 nucleotides from the ATG initiation codon. In addition we found that none of $\mathrm{CpG}$ dinucleotides in the in the $H S D 17 B 10$ proximal promoter $\mathrm{CpG}$ island region, approached 50\% methylation in female genomic DNA. Since X inactivation of $H S D 17 B 10$ would be expected to result in nearly complete methylation of

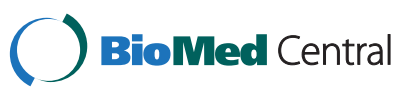


this region in one of the two copies of this gene, this hypomethylation of the $\mathrm{CpG}$ island, together with previously reported data of $H S D 17 B 10$ expression in somatic cell hybrids [16], suggests that this gene may have a variable escape from X-chromosome inactivation.

\section{Methods}

\section{Ethics statement}

This study was approved by the Institutional Review Board of NYS Institute for Basic Research in Developmental Disabilities. The human DNA samples were obtained in conformance with the Internal Review Board's guidelines and included the acquisition of written informed consent.

\section{Chromosomal DNA}

Chromosomal DNA was isolated from blood samples of normal individuals (one male and two females) with the FlexiGene kit (www.qiagen.com) and used as the template for the HSD17B10 gene-specific methylation analysis.

\section{Primer extension analysis}

Total human brain RNA was purchased from Clontech. A primer HBHADPE3 (5'-CAGGTCCAGAAGCACA GCAGAGGCT-3') specific to HSD17B10 [17] was synthesized. This primer and phiX174 DNA/Hinf1 marker obtained from Promega were 5'-labeled, respectively, by using $\left[\gamma^{-}{ }^{32} \mathrm{P}\right] \mathrm{ATP}$ and T4 polynucleotide kinase as previously described [18]. 25 $\mathrm{g}$ guman brain RNA mixed with 1 pmol of ${ }^{32} \mathrm{P}$-labeled primer in $17 \mu \mathrm{l}$ of buffer containing $75 \mathrm{mM}$ KOAc, $50 \mathrm{mM}$ Tris-HCL (pH 8.3), 8 $\mathrm{mM} \mathrm{Mg}(\mathrm{OAc})_{2}$, and $10 \mathrm{mM}$ DTT was denatured in a heating block set at $100^{\circ} \mathrm{C}$ for $2 \mathrm{~min}$, and then cooled quickly on ice. This sample was transferred to a $42^{\circ} \mathrm{C}$ water bath for hybridization for at least $30 \mathrm{~min}$. During the annealing reaction, the sample was mixed with $2 \mu \mathrm{l}$ dNTP (2mM each of dATP, dGTP, dTTP and $10 \mu \mathrm{Ci}$ $\left.\left[\alpha{ }^{32} \mathrm{P}\right] \mathrm{dCTP}\right)$ and $1 \mu \mathrm{l}$ of AMV reverse transcriptase (20 units). Finally, $2 \mathrm{mM} \mathrm{dCTP}$ was added and the extension reaction proceeded at $42^{\circ} \mathrm{C}$ for another $30 \mathrm{~min}$, as previously described in principle [19]. Three parallel experiments, either without RNA or without primer or without reverse transcriptase, were performed as controls. At the end of the primer extension, $4 \mu \mathrm{l}$ of $0.5 \mathrm{M}$ EDTA was added to stop the reaction. After the nucleic acid was recovered by ethanol precipitation, the pellet was resuspended in $6 \mu \mathrm{l}$ of formamide gel loading buffer. Primer extension products were separated by electrophoresis on an $8 \%$ polyacrylamide gel in parallel with the $\left[\gamma_{-}{ }^{32} \mathrm{P}\right]$-labeled phiX174 DNA/Hinf1 marker and a dideoxy sequencing ladder from the dideoxy sequencing of a plasmid containing the HSD17B10 5'-flanking region ligated to the same gene's coding sequence.

\section{Bisulfite sequencing}

Bisulfite modification and pyrosequencing analyses [20] of a 179 bp segment of the 5'-flanking region of the HSD17B10 gene was done by EpigenDx, Inc. (www. epigendx.com) using the Zymo Research EZ methylation kit (www.zymoresearch.com), Hotstar Taq polymerase (www.qiagen.com), the PSQ ${ }^{\mathrm{m}} 96 \mathrm{HS}$ system, and EpigenDx HSD17B10 methylation assay kit (ADS2502FS). For experimental details the ASSAY DESIGN REPORT of the EpigenDx Inc. is included as the Additional file 1. The target sequence and pyrosequencing analysis are listed in Table 1.

\section{Results}

Multiple transcription start sites of HSD17B10 gene

The primer used for primer extension is complementary to the HSD17B10 cDNA 102 to 126 nucleotides downstream from the ATG initiation codon. The results of a representative analysis are presented in Figure 1. The sizes of two prominent bands ( $a$ and $b$ ) show that two major transcription start sites are located in the 5'-flanking region of the HSD17B10 gene at -37 and -6 base pairs upstream from the ATG initiation codon. A minor band (c) corresponds to an additional transcription start site at -12 upstream from the ATG, exactly matching the start position of a known HSD10 transcript HIT000033911. Also bands (b) and (c) correspond closely to the transcription start sites displayed in the ENCODE project [21] but both are one nucleotide further upstream.

\section{Hypomethylation of the $\mathrm{CpG}$ island in $5^{\prime}$-fflanking region of the HSD17B10 gene}

The 5'-flanking region of the HSD17B10 gene contains a $\mathrm{CpG}$ island, consisting of $23 \mathrm{CpG}$ dinucleotides in a region from -171 to - 6 bp upstream from the ATG initiation condon (Table 1). An epigenetic analysis was performed for the $H S D 17 B 10$ proximal promoter. As expected few $(<3 \%)$ of cytosines in $\mathrm{CpGs}$ of this promoter were found to be 5-methylated in male DNA (Figure 2). On the other hand, about $20 \%$ of cytosines in CpG dinucleotides were determined to be 5-methylated in females. In contrast with other genes subject to X-chromosome inactivation (XCI) [21], the HSD17B10 proximal promoter was found not to be hypermethylated: none of CpG dinucleotides in this region approached 50\% C5-methylation in the female DNAs analyzed.

\section{Discussion}

HSD10 which is encoded by the HSD17B10 gene [17], has both enzymatic and non-enzymatic functions that are central to a number of developmental disabilities and AD [22]. The HSD17B10 proximal promoter has a CCAAT box (-56/-52 from ATG), but no TATA box 
Table 1 Methylation assay target sequences

\begin{tabular}{llll}
\hline Assay ID & \multicolumn{1}{c}{ Genomic target sequence } & Bisulfite converted target sequence & Pyrosequencing dispensation order \\
\hline ADS2502FS1 & $\begin{array}{l}\text { caggcggaatccgccctctggccaaaggactag } \\
\text { cgtaccagg }\end{array}$ & taggyggaattygttttttggttaaaggattagygtattagg & ATCATGTCGTATCGTCTGCTAGACTATGTCGTA \\
\hline ADS2502FS1 & ccacgccccacgtctcatgcggcagcggcagac & ttaygttttaygttttatgyggtagyggtagaygtttyggtt & TCGATCGTCTGATCGTCTATAGTCGTCATGTCG \\
& gccccggcccgtcgatccgccccttccgccgctt & ygtygtattygttttttygtygt/gttygtttyggttaattaay & TAGTATCAGTCGTCAGTCGTCGATCGTCAGT \\
& cgcctcggccaatcaacgagcgcccgcgcccc & gagygagygttygygttttattTTATITYGTGGAGTG & CGTTCTGTCGTCATCGATCGATGTCAGTCGTC \\
& atcCCCATCCCGTGGAGTGGCCGGCGA & GTYGGYGATAAGATGG & GTCTATTGATCGTGAGTAGTCGTCGA \\
& CAAGATGG (c>g, polymorphism rs1264014) & & \\
\hline
\end{tabular}

(Figure 1B). So far fourteen different types of hydroxysteroid (17 $\beta$ ) dehydrogenases have been identified in mammalian cells [23]. Genes encoding different types of hydroxysteroid (17ß) except that for the type 1 hydroxysteroid (17 $\beta$ ) dehydrogenase (HSD17B1), have a binding site for CCAAT enhancer binding factors (C/ EBPs) in their promoters. A study focused on the impact of this family of transcription factors on gene expression in a hepatocarcinoma cell line HepG2 found that both $H S D 17 B 8$ and $H S D 17 B 10$ were regulated by C/EBP $\beta$ [24].

Three splice variants of HSD10 have been reported [1]. Since the ratio of HSD10 mRNA isoform 1 versus those of 2 and 3 is 3280:1:52 [1], the transcription start sites identified in this study are most likely related to the transcript of HSD10 variant 1 and probably to 2 and 3 as well, although this remains to be determined.

It was reported that there is approximately a 5-fold increase of HSD10 antigen in cortical neurons in the region surrounding cerebral ischemia consequent to stroke [13]. This observation suggest that the HSD17B10 may be a hypoxia-responsive gene. Moreover, a significant change of HSD17B10 expression was found in the colonic mucosa of patients with ulcerative colitis $[14,15]$. We examined alternative transcription start sites because alternative transcription start site usage has been linked to disease [25]. The first major transcription start site in human brain was identified 37 nucleotides upstream from the ATG initiation codon (see "a" in Figure 1B). This is 6 nucleotides upstream from the start of Ref. Seq NM_004493.2 (Figure 1B), which is itself 6 nucleotides upstream from the start site in the sequence we originally deposited to GenBank (AF035555.1) in 1997. The results indicate that the actual length of first exon of this gene is about one and a quarter of that reported previously [17]. The multiple transcription start sites identified here not only locate the RNA polymerase II binding sites but also suggest that the transcription complex may shift within this promoter.

The HSD17B10 promoter qualifies as a high CpG density (HC) promoter (see Table 1 ), which is often associated with housekeeping genes [26]. The association between promoter methylation and transcriptional silencing is well established and promoter methylation is a reliable epigenetic mark of XCI [27]. The methylation analysis of a CpG island that overlaps a promoter, along with measurements of the relative expression of each allele identified by SNPs or expression analysis in somatic cell hybrids $[16,28,29]$, is one of the most useful methods
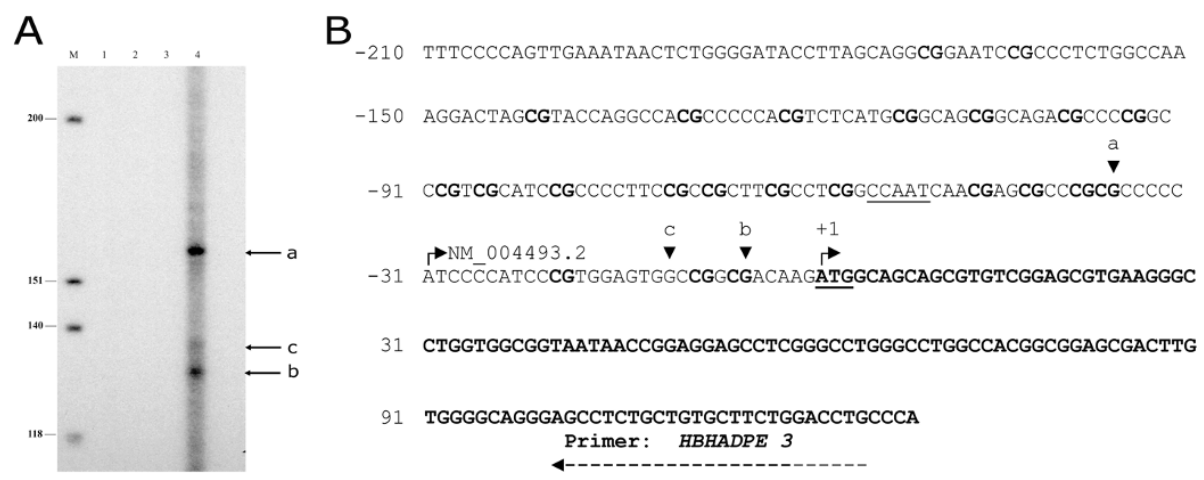

Figure 1 Transcription start sites of human HSD17B10 gene were determined by primer extension. Part A: (M), DNA molecular standards of which the sizes (bp) are indicated; (1), controls run without reverse transcriptase; (2), without RNA; (3), without primer; and (4), extension reaction mixture analyzed in parallel on an $8 \%$ polyacrylamide gel. The dideoxy sequencing ladder is included in the Additional file 2 . Part $\mathbf{B}$ : Two major transcription start sites at -37 and -6 , respectively, and a minor one at -12 are indicated by vertical arrowheads $a, b$, and c, respectively. CpG dinucleotides in the proximal promoter and the HSD17B10 CDNA nucleotide sequence are in bold. The oligonucleotide primer used in this study was complementary to a fragment of the HSD17B10 cDNA nucleotide sequence, and is shown by a long dash arrow. Both the initiation codon ATG, numbered as +1 , and the CCAAT box are underlined. 


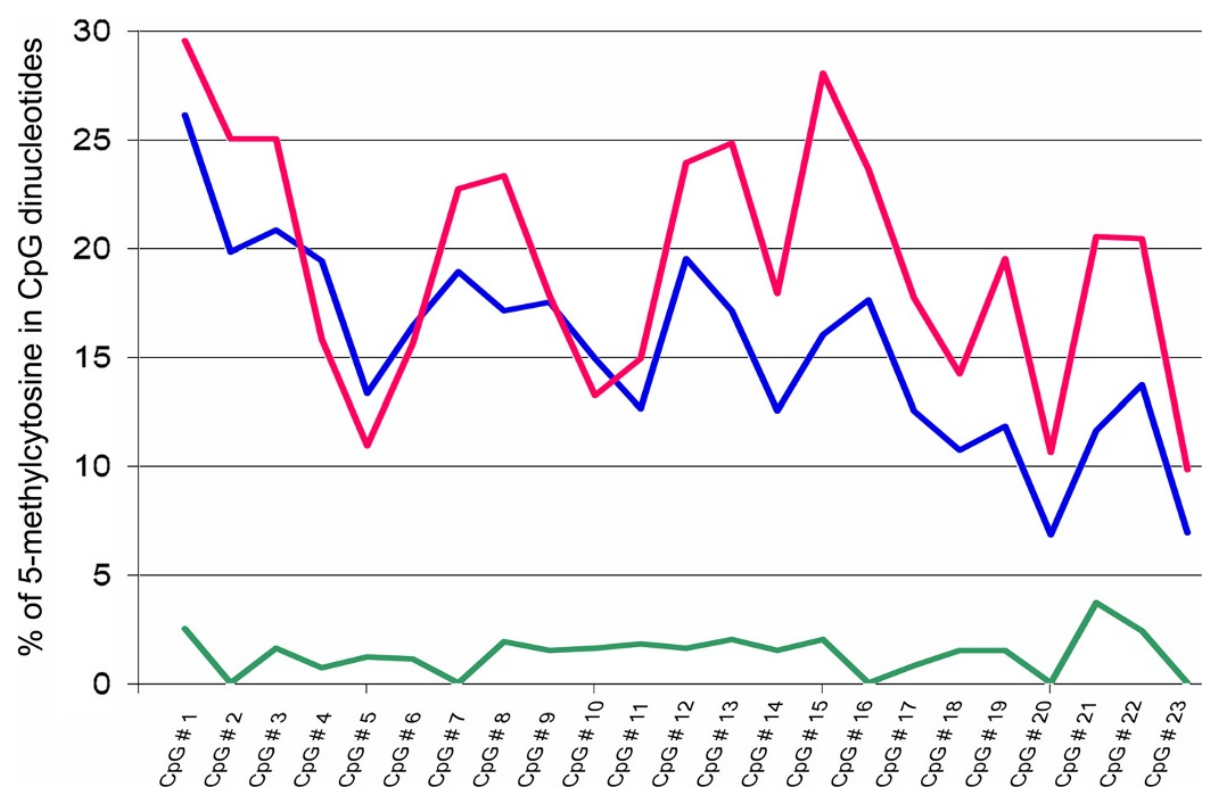

Figure 2 Methylation analysis of the proximal promoter of HSD17B10 gene. The percentage of 5-methylcytosines in different CpG dinucleotides is shown on the vertical axis. The nucleotide position for individual CpG dinucleotides can be found in Table 1 in the "Genomic Target Sequence" column. Red and blue lines represent the results obtained from two normal females while the green line shows the results from a normal male.

to predict the genes that escape XCI [30]. The epigenetic analysis of the HSD17B10 proximal promoter showed that it is unmethylated in male DNA $(<3 \%$ 5methylcytosine) as expected, but that only about $20 \%$ of the cytosines in CpG dinucleotides is methylated in female DNA (Figure 2). Since CpG island-containing promoters are usually highly methylated on the inactive $\mathrm{X}$ and unmethylated on the active $\mathrm{X}$, analysis of female DNA usually shows approximately $50 \%$ methylation of CpG islands of genes subject to XCI. This is the net result of approximately $100 \%$ methylation of genes on the inactive $\mathrm{X}$ and their complete lack of methylation on the active X. Analysis of male DNA shows only the pattern of the active $\mathrm{X}$-the absence of methylation [27]. Thus the remarkably low methylation level of this $\mathrm{HC}$ promoter is consistent with the results from expression of the $H S D 17 B 10$ gene in hybrids showing escape from XCI $[16,28,29]$.

Chromosomal DNA isolated from blood is widely used for the methylation analysis of X-linked promoters as leukocytes are non-dividing cells with a short life span [31]. Since it was reported that at least $88 \%$ of human genes do not show tissue-specific XCI [27], data obtained from blood chromosomal DNA generally represents the $\mathrm{XCI}$ status in other tissues. This is true for the gene of interest, because the methylation profile of the $H S D 17 B 10$ proximal promoter shown in Figure 2 was found to be like that of human dorsolateral prefrontal cortex according to the methylomeDB, a database of DNA methylation profiles of the brain [32].
Hypomethylation of this promoter was found in both blood and brain. Although it was previously reported in a study of fibroblasts $[33,34]$ that the HSD17B10 gene did not escape XCI, the opposite inference [16] is implied by the data presented here. Data from epigenetic analysis of the HSD17B10 proximal promoter is consistent with a variable escape of this gene from XCI. This suggests that some bi-allelic expression of this gene may occur in female cells, which could add to the variability in expression imposed by mosaicism of XCI [35]. It is conceivable that the variable escape may allow more cells to have at least some wild type HSD10 in a female carrying a missense mutation on the HSD17B10 gene.

Missense mutations of the HSD17B10 gene result in an X-linked metabolic disease in males while most females are asymptomatic [36]. So far only two female cases with severe developmental disabilities have been reported $[37,38]$. More interestingly, female patients uniformly present milder clinical manifestations than male patients carrying the same mutations. The variable escape of the HSD17B10 gene from XCI may provide another protective factor for a female for alleviation of HSD10 deficiency.

\section{Conclusions}

The actual length of first exon of the HSD17B10 gene was found to be about a quarter larger than that originally reported. Its transcripts result from a slippery transcription complex. The hypomethylation of the $\mathrm{CpG}$ island in the proximal promoter of the HSD17B10 gene 
provides additional evidence for the variable escape of the HSD17B10 gene from X-chromosome inactivation which could influence the range of severity of HSD10 deficiency, an inherited error in isoleucine metabolism, in heterozygous females.

\section{Additional files}

\section{Additional file 1: ASSAY DESIGN REPORT of the EpigenDx Inc.}

Additional file 2: The dideoxy sequencing ladder: $C$, cytosine; $T$, thymine; A, adenine; G, guanosine; M, pBR322 DNA Mspl Digest.

\section{Competing interests}

The authors declare that they have no competing interests.

\section{Authors' contributions}

SYY, CD and WTB conceived the study. XYH, CD and SYY performed experiments. SYY and CD drafted the manuscript. All authors have read and approved the final manuscript.

\section{Authors' information}

SYY: MD, PhD, email: songyu.yang@csi.cuny.edu, Head of the Medical Biochemistry Lab:

CD: PhD, email: Carl.Dobkin@opwdd.ny.gov, Head of the Molecular Genetics Lab;

XYH: PhD, email: xue-ying.he@opwdd.ny.gov, Senior Scientist:

WTB: MD, PhD, ted.brown@opwdd.ny.gov, Director of the NYSIBRDD.

\section{Acknowledgements}

This work was supported by the New York State Office for People with Developmental Disabilities. We thank Dr. M. Junaid for his help in collecting data and two anonymous reviewers for their comments.

\section{Author details}

${ }^{1}$ Department of Developmental Biochemistry, NYS Institute for Basic Research in Developmental Disabilities, 1050 Forest Hill Road, Staten Island, NY 10314, USA. ${ }^{2}$ Department of Human Genetics, NYS Institute for Basic Research in Developmental Disabilities, 1050 Forest Hill Road, Staten Island, NY 10314, USA.

Received: 27 March 2013 Accepted: 2 July 2013

Published: 8 July 2013

\section{References}

1. Yang SY, He XY, Miller D: HSD17B10: A gene involved in cognitive function through metabolism of isoleucine and neuroactive steroids. Mol Genet Metab 2007, 92:36-42.

2. He XY, Yang SY: Roles of type 10 17beta-hydroxysteroid dehydrogenase in intracrinology and metabolism of isoleucine and fatty acids. Endoc Metab Immun Dis - Drug, Targets 2006, 6:95-102.

3. Yang SY, He XY, Schulz H: Multiple functions of type $1017 \mathrm{beta}-$ hydroxysteroid dehydrogenase. Trends Endocrinol Metab 2005, 16:167-175.

4. Holzmann J, Frank P, Löffler E, Bennett KL, Gerner C, Rossmanith W: RNase P without RNA: identification and functional reconstitution of the human mitochondrial tRNA processing enzyme. Cell 2008, 135:462-474.

5. Oppermann UC, Salim S, Tjernberg LO, Terenius L, Jornvall H: Binding of amyloid $\beta$-peptide to mitochondrial hydroxyacyl-CoA dehydrogenase (ERAB): regulation of an SDR enzyme activity with implication for apoptosis in Alzheimer's disease. FEBS Lett 1999, 451:238-242.

6. Jazbutyte V, Kehl F, Neyses L, Pelzer T: Estrogen receptor alpha interacts with 17beta-hydroxysteroid dehydrogenase type 10 in mitochondria. Biochem Biophys Res Commun 2009, 384:450-454.

7. Yang S-Y, He X-Y, Olpin SE, Sutton VR, McMenamin J, Philipp M, Denman RB, Malik M: Mental retardation linked to mutations in the HSD17B10 gene interefering with neurosteroid and isoleucine metabolism. Proc Nat/ Acad Sci USA 2009, 106:14820-14824.

8. Seaver LH, He XY, Abe K, Cowan T, Enns GM, Sweetman L, Lee S, Malik M, Yang SY: A novel mutation in the HSD17B10 gene of a 10-year-old boy with refractory epilepsy, chreoathetosis and learning disability. PLoS One 2011, 6:e27348.

9. Lenski C, Kooy RF, Reyniers E, Loessner D, Wanders RJA, Winnepenninckx B, Hellebrand H, Engert S, Schwartz CE, Meindl A, Ramser J: The reduced expression of the $\mathrm{HADH} 2$ protein causes $\mathrm{X}$-linked mental retardation, choreoathetosis, and abnormal behavior. Am J Hum Genet 2007, 80:372-377.

10. Yang SY, He XY: Role of type 1017 beta-hydroxysteroid dehydrogenase in the pathogenesis of Alzheimer's disease. In Neuropathology and Genetics of Dementia. Edited by Tolnay M, Probst A. New York: Kluwer Academic; 2001:101-110.

11. Kristofiková Z, Bocková M, Hegnerová K, Bartos A, Klaschka J, Rícný J, Rípová D, Homola J: Enhanced levels of mitochondrial enzyme 17betahydroxysteroid dehydrogenase type 10 in patients with Alzheimer disease and multiple sclerosis. Mol Biosyst 2009, 5:1174-1179.

12. He XY, Wegiel J, Yang YZ, Pullarkat R, Schulz H, Yang SY: Type 10 17betahydroxysteroid dehydrogenase catalyzing the oxidation of steroid modulators of $\gamma$-aminobutyric acid type A receptors. Mol Cell Endocrinol 2005, 229:111-117.

13. Yan SD, Zhu Y, Stern ED, Hwang YC, Hori O, Ogawa S, Frosch MP, Conolly ES Jr, McTaggert R, Pinsky DJ, Clarke S, Stern DM, Ramasamy R: Amyloid $\beta$-peptide-binding alcohol dehydrogenase is a component of the cellular response to nutritional stress. J Biol Chem 2000, 275:27100-27109.

14. He XY, Yang YX, Yang SY: Changes of the HSD17B10 gene expression levels in ulcerative colitis. Inflamm Bowel Dis 2013, 19:E23-E24.

15. De Preter V, Arijs I, Windey K, Vanhove W, Vermeire S, Schuit F, Rutgeerts P, Verbeke $\mathrm{K}$ : Impaired butyrate oxidation in ulcerative colitis is due to decreased butyrate uptake and a defect in the oxidation pathway. Inflamm Bowel Dis 2012, 18:1127-1136.

16. He XY, Dobkin C, Yang SY: Does the HSD17B10 gene escape from X-inactivation? Eur J Hum Genet 2011, 2011(19):123-124.

17. He XY, Schulz H, Yang SY: A human brain L-3-hydroxyacyl-CoA dehydrogenase is identical with an amyloid $\beta$-peptide binding protein involved in Alzheimers disease. J Biol Chem 1998, 273:10741-10746.

18. Chaconas $\mathrm{G}$, van der Sande $\mathrm{JH}: \mathrm{z}^{-32} \mathrm{P}$ labeling of RNA and DNA fragments. Methods Enzymol 1980, 65:75-85.

19. He Yang $X Y$, Schulz H, Elzinga M, Yang SY: Nucleotide sequence of the promoter and fadB gene of the fadBA operon and primary structure of the multifunctional fatty acid oxidation protein from E. coli. Biochemistry 1991, 30:6788-6795.

20. Sheridan SD, Theriault KM, Reis SA, Zhou F, Madison JM, Daheron L, Loring $J F$, Haggarty SJ: Epigenetic characterization of the FMR1 gene and aberrant neurodevelopment in human induced pluripotent stem cell models of fragil X syndrome. PLoS One 2011, 6:e26203.

21. Kavanagh DH, Dwyer S, O'Dovovan MC, Owen MJ: The ENCODE project: implication for psychiatric genetics. Mol Psychiatry 2013, 18:540-542.

22. Yang SY, He XY, Miller D: Hydroxysteroid (17ß) dehydrogenase $X$ in human health and disease. Mol Cell Endocrinol 2011, 343:1-6.

23. Moeller G, Adamski J: Integrated view on 17beta-hydroxysteroid dehydrogenases. Mol Cell Endocrinol 2009, 301:7-19.

24. Rotenin M, Villar J, Celay J, Encio I: Type 10 17ß-hydroxysteroid dehydrogenase expression is regulated by C/EBP $\beta$ in HepG 2 cells. J Steroid Biochem Mol Biol 2010, 122:164-171.

25. Thorsen K, Schepeler T, Oster B, Rasmussen MH, Vang S, Wang K, Hansen KQ, Lamy P, Pedersen JS, Eller A, Mansilla F, Laurila K, Wiuf C, Laurberg S, Dyrskjøt L, Ørntoft TF, Andersen CL: Tumor-specific usage of alternative transcription start sites in colorectal cancer identified by genome-wide exon array analysis. BMC Genomics 2011, 12:505

26. Weber M, Hellmann I, Stadler MB, Ramos L, Paabo S, Rebhan M, Schübeler $D$ : Distribution, silencing potential and evolutionary impact of promoter DNA methylation in the human genome. Nature Genet 2007, 39:457-466.

27. Cotton AM, Lam L, Affleck JG, Wilson IM, Penaherrera MS, McFadden DE, Kobor MS, Lam WL, Robinson WP, Brown CJ: Chromosome-wide DNA methylation analysis predicts human tissue-specific $\mathrm{X}$ inactivation. Hum Genet 2011, 130:187-201.

28. Miller AP, Willard HF: Chromosomal basis of $\mathbf{X}$ chromosome inactivation: identification of a multigene domain in Xp11.21-p. 11.22 that escapes $X$ inactivation. Proc Natl Acad Sci USA 1998, 95:8709-8714.

29. Carrel L, Willard HF: X-inactivation profile reveals extensive variability in X-linked gene expression in females. Nature 2005, 434:400-404.

30. Sharp AJ, Stathaki E, Migiavacca E, Brahmachary M, Montgomery SB: DNA methylation profiles of human active and inactive $X$ chromosomes. Genome Res 2011, 21:1592-1600. 
31. Yasukochi Y, Maruyama O, Mahaian MC, Padden C, Euskirchen GM: X chromosome-wide analyses of genomic DNA methylation states and gene expression in male and female neutrophis. Proc Natl Acad Sci USA 2010, 107:3704-3709.

32. Xin Y, Chanrion B, O'Donnell AH, Milekic M, Costa R, Ge Y, Haghighi FG: MethylomeDB: a database of DNA methylation profiles of the brain. Nucleic Acids Res 2012, 40:D1245-D1249.

33. Garciar-Villoria J, Gort L, Madrigal I, Fons C, Fernandez C, Navarro-Sastre A, Milà M, Briones P, García-Cazorla A, Campistol J, Ribes A: X-inactivation of HSD17B10 revealed by CDNA analysis in two female patients with 17ßhydroxysteroid dehydrogenase 10 deficiency. Eur I Hum Genet 2010, 18:1353-1356.

34. Garciar-Villoria J, Gort L, Madrigal I, Fons C, Fernandez C, Navarro-Sastre A, Milà M, Briones P, García-Cazorla A, Campistol J, Ribes A: Reply to He et al. Eur J Hum Genet 2011, 19:124.

35. Berletch JB, Yang F, XU J, Carrel L, Disteche CM: Genes that escape from X inactivation. Hum Genet 2011, 130:237-245.

36. Yang SY, Dobkin C, He XY, Phillip M, Brown WT: A 5-methylcytosine hotspot responsible for the prevalent HSD17B10 mutation. Gene 2013, 515:380-384.

37. Ensenauer R, Niederhoff $H$, Ruiter JP, Wanders RJ, Schwab KO, Brandis M, Lehnert W: Clinical variability in 3-hydroxy-2-methylbutyryl-CoA dehydrogenase deficiency. Ann Neurol 2002, 51:656-659.

38. Garciar-Villoria J, Navarro-Sastre A, Fons C, Pérez-Cerdá C, Baldellou A, Fuentes-Castelló MA, González I, Hernández-Gonzalez A, Fernández C, Campistol J, Delpiccolo C, Cortés N, Messeguer A, Briones P, Ribes A: Study of patients and carriers with 2-methyl-3-hydroxybutyryl-CoA dehydrogenase (MHBD) deficiency: difficulties in the diagnosis. Clin Biochem 2009, 42:27-33.

doi:10.1186/1471-2091-14-17

Cite this article as: Yang et al:: Transcription start sites and epigenetic analysis of the HSD17B10 proximal promoter. BMC Biochemistry 2013 14:17.

\section{Submit your next manuscript to BioMed Central and take full advantage of:}

- Convenient online submission

- Thorough peer review

- No space constraints or color figure charges

- Immediate publication on acceptance

- Inclusion in PubMed, CAS, Scopus and Google Scholar

- Research which is freely available for redistribution 